\title{
The Trajectories of Adolescents' Perceptions of School Climate, Deviant Peer Affiliation, and Behavioral Problems During the Middle School Years
}

\author{
Ming-Te Wang \\ University of Michigan
}

\author{
Thomas J. Dishion \\ University of Oregon
}

This longitudinal study examined trajectories of change in adolescents' perceptions of four dimensions of school climate (academic support, behavior management, teacher social support, and peer social support) and the effects of such trajectories on adolescent problem behaviors. We also tested whether school climate moderated the associations between deviant peer affiliation and adolescent problem behaviors. The 1,030 participating adolescents from eight schools were followed from sixth through eighth grades (54\% female; $76 \%$ European American). Findings indicated that all the dimensions of school climate declined, and behavioral problems and deviant peer affiliation increased. Declines in each dimension were associated with increases in behavioral problems. The prediction of problem behavior from peer affiliation was moderated by adolescents' perceptions of school climate.

As adolescents transition to middle school, they confront a series of new social and educational demands that place some of them at greater risk for the development of behavioral problems (Reinke \& Herman, 2002). There has been considerable evidence that the academic and social climate of middle schools influences students' adjustment across multiple domains (Roeser, Eccles, \& Sameroff, 2000; Wang, 2009). Although the majority of research on school climate has focused on academic outcomes, interest and evidence for the impact of school climate on behavioral and psychological ones have increased over the past 10 years (Wang and Eccles, In press-a). However, most studies of school climate have primarily addressed how students' perceptions change during the transition from elementary to middle school, and have not examined the changing patterns of students' perceptions during the middle school years (Way, Reddy, \& Rhodes, 2007).

An ecological approach posits that the development of adolescent problem behaviors stems from complex and dynamic processes among various social contexts with which adolescents interact (Bronfenbrenner, 1986). During early adolescence, peers become a primary determinant for social and emotional development (Way \& Greene, 2006).

We thank Cher Mikkola and Margaret Rundle for their feedback on the earlier version of this manuscript. This project was supported by grants DA 018760, DA 07031, and DA 13773 from the National Institute on Drug Abuse at the National Institutes of Health to Thomas J. Dishion.

Requests for reprints should be sent to Ming-Te Wang, University of Michigan, ISR 5110, 426 Thompson St., Ann Arbor, MI 48106. E-mail: wangmi@umich.edu
Youth begin to spend considerably more time outside the home, which increases their interactions with peers (Simons-Morton, Crump, Haynie, \& Saylor, 1999). As youth experience the increasing demands of behavioral autonomy and independence from parents, they are also more likely to turn to their friends as sources of support and influence (Wang, Dishion, Stormshak, \& Willett, 2011). Risky peer groups commonly model and support deviant behavior, provide opportunities to engage in deviant behavior, and offer positive reinforcement for deviant behavior (Dishion, 2000; Dishion \& Patterson, 2006). A variety of factors could potentially moderate the level of influence of deviant peers, including the manner in which schools are managed and organized by teachers and school staff. In fact, research on school characteristics shows that specific school features may function as protective factors that buffer the effects of risky peer groups and enhance prosocial peer interactions (Crosnoe, Erickson, \& Dornbusch, 2002). However, little research has examined the role of school climate in moderating or buffering the effects of peer contagion on problem behaviors during the middle school years, despite the fact that early adolescence is a sensitive developmental period for peer effects (Dishion, Nelson, Winter, \& Bullock, 2004).

In this study, we used latent growth curve models to examine trajectories of change in adolescents' perceptions of four critical dimensions of school

(C) 2011 The Authors

Journal of Research on Adolescence (C) 2011 Society for Research on Adolescence DOI: $10.1111 /$ j.1532-7795.2011.00763.x 
climate (academic support, school behavior management, teacher social support, and peer social support) from sixth through eighth grades, and the effects of such trajectories on the development of adolescent problem behaviors. We also examined whether school climate moderated the associations between deviant peer affiliation and adolescent problem behaviors.

\section{THEORETICAL AND EMPIRICAL BACKGROUND}

This study used an ecological model to understand adolescent perceptions of school climate and their relation to the development of problem behaviors (Bronfenbrenner, 1986). The ecological model proposes that students in the same school may have unique experiences and perceptions based on their specific social interaction patterns with peers and teachers (Eccles, Lord, \& Roeser, 1995). Students' perceptions of the teacher and peer environment at school, in turn, are prognostic of future adaptations (Ensminger, Kellam, \& Rubin, 1981). For example, students who feel that teachers in their school are unsupportive become less motivated to work and engage academically (Wang \& Holcombe, 2010). Thus, we used students' self-reports of school climate to focus on how the students themselves derived meaning from their own perceptions of the school environment.

The transition to middle school often signals multiple transitions, including a less intimate physical space and fewer personal connections with a primary supportive teacher (Eccles et al., 1993). This transition appears to be more challenging for some students and places them at greater risk for the development of problem behaviors. The changes in school organization occur just when a more positive school environment might provide the predictable routines, appropriate adult role models, and emotional support that are particularly beneficial for those adolescents with disruptive, chaotic home, and community environments (Wang et al., 2011).

\section{SCHOOL CLIMATE PERCEPTIONS AND BEHAVIORAL PROBLEMS}

Four dimensions of the public middle school environment are particularly germane: (1) academic support, (2) school behavior management, (3) teacher social support, and (4) peer social support (Kuperminc, Leadbeater, \& Blatt, 2001; Roeser \& Eccles, 1998). These characteristics are considered particularly important for adolescents during the middle school years, because they correspond to the developmental needs of early adolescents for competency and relatedness (Connell \& Wellborn, 1991; Eccles, Lord, \& Midgley, 1991). Researchers note that a sense of competency will often emerge in an environment that is fair and consistent and that provides appropriate academic support and expectations (Connell \& Wellborn, 1991; Gottfredson, Gottfredson, \& Hybl, 1993). To support students' sense of belonging, the school climate must demonstrate interest in individual students and include emotional support provided by teachers and other students (Wang and Eccles, in press-b); Wentzel, 1998).

Empirical studies have suggested that student perceptions of academic support, behavior management, teacher social support, and peer social support are strongly associated with their behavioral adjustment (Kuperminc, Leadbeater, Emmons, \& Blatt, 1997; Wang, Selman, Dishion, \& Stormshak, 2010). Academic support refers to the extent to which the school emphasizes and creates a supportive learning environment with high academic expectations and many opportunities for reinforcement (Crone \& Horner, 2003). Students who perceive strong academic support in school are more likely to be academically motivated and have fewer behavioral problems (Weishew \& Peng, 1993). Conversely, students who experience repeated failures in academics are less inclined to perceive their school as academically supportive and may reduce their commitment to student roles and their motivation to perform well, and increase school problem behavior (McEvoy \& Welker, 2000).

Attention to the behavior management of students in public middle school has been shown to be associated with lower levels of problem behavior (Crone \& Horner, 2003; Gottfredson, 1990). School behavior management involves the extent to which the school provides clear and consistent rules and discipline, and adults treat students in a fair and equitable manner. Students who report that their schools establish, communicate, and enforce a fair discipline system with clear rules and consequences have fewer problem behaviors and avoid victimization (Griffith, 1999). Again, individual perceptions of the school's behavior management may explain the students' tendency to engage in problem behavior or reflect the collective skills of school staff to manage behavior.

Finally, the quality of interpersonal relationships in school, including student-teacher relationships and peer relationships, plays an essential role in 
the development of student problem behaviors. Students who perceive that teachers are supportive, responsive, and care about them have better academic performance and fewer behavior problems (Loukas \& Robinson, 2004; Wang, 2009). Similarly, the quality of friendships can foster or undermine adolescents' social and emotional growth (Way \& Greene, 2006). Peer acceptance and positive peer interactions have been negatively associated with adolescents' behavioral and emotional problems (Stewart, 2003). A well-established literature links problem behavior to peer rejection in school (Coie \& Kupersmidt, 1983; Dodge, 1983), and in turn, peer rejection at school predicts future deviant peer involvement (Dishion, Patterson, Stoolmiller, \& Skinner, 1991) and problem behavior in the future (Nelson \& Dishion, 2004).

Taken together, these studies indicate the range of behavioral outcomes associated with students' perceptions of middle school environments and underscore how important the perception of school environments is to behavioral adjustment in early adolescence (Gottfredson \& Gottfredson, 2001; Roeser \& Eccles, 1998). However, existing studies have relied primarily on cross-sectional data or have used methods of analysis (e.g., repeated measures analysis of variance) that do not address the developmental complexity of change in perceptions of the school environment and changes in behavior over time (Wang et al., 2010). Moreover, extant research has typically treated students' perceptions of school climate as static, baseline predictors of adolescent outcome variables rather than as dynamic processes that also change over time (Way et al., 2007). Shifts in any dimension of school climate, such as teacher support or peer support, are likely to have implications for behavioral adjustment. In this study, we extended prior research of school climate by modeling the longitudinal trajectories of school climate perceptions from sixth through eighth grades and by investigating the effects of different patterns of school climate perceptions on adolescent problem behaviors.

\section{GENDER DIFFERENCES}

As adolescent boys and girls often differ in their patterns of development and socialization, their perceptions of school climate may vary. Research has suggested that boys perceive school environments in a less favorable light than do girls as a result of bias for expectations and behaviors that favor girls (Wang, 2009; Way et al., 2007).
However, current research on gender difference as a moderator of school climate effects on student problem behaviors is less consistent. For example, while examining the effects of school climate on problem behaviors, some studies found that the relationships were significant for both boys and girls, but stronger for boys (Kuperminc et al., 1997; Seidman, Allen, Aber, Mitchell, \& Feinman, 1994), whereas other studies have demonstrated no gender differences in the relationships (Colarossi \& Eccles, 2003). Crosnoe et al. (2002) identified different patterns of risk and protective factors for boys and for girls, depending on the outcome of interest. Boys with positive school engagement and orientation tended to have lower levels of alcohol use, and girls who had strong relationships with teachers tended to have lower illegal drug use. Clearly, more work is needed that investigates the possible ways in which school climate perceptions might affect boys and girls differently.

\section{THE MODERATING ROLE OF SCHOOL CLIMATE PERCEPTIONS BETWEEN DEVIANT PEER AFFILIATION AND PROBLEM BEHAVIOR}

Extant research demonstrates that at-risk peer relationships provide a context for the development of problem behaviors. Involvement with delinquent peer groups is a strong predictor of a variety of problematic outcomes for adolescents, including substance use and antisocial behavior (Bullock, Deater-Deckard, \& Leve, 2006). However, it is not clear how school and peers jointly influence adolescent behaviors. Recent studies show that the relation between deviant peers and adolescent problem behavior may interact with the quality of school climate. For example, teachers and staff who are closely involved with the students and who actively monitor the school environment appear to be an important component in deterring the influence of deviant peer groups (Dishion, Bullock, \& Granic, 2002). Some study findings have shown that poor teacher-student relationships increase the probability that adolescents will affiliate with deviant peers and that more associations with deviant peers, in turn, will result in externalizing problems (Cleveland \& Wiebe, 2003). Considering the extent to which peers contribute to adolescent behavior, we chose to investigate the school climate and interactions with peer contexts that have an impact on adolescents' behavioral outcomes during the middle school years. 


\section{OVERVIEW OF THE CURRENT STUDY}

In this longitudinal study, we aimed to examine the following three research questions. (1) How do adolescents' perceptions of academic support, school behavior management, teacher social support, and peer social support change from sixth through eighth grades? Do changes in perceptions of these four dimensions of school climate differ by adolescent gender? (2) Are changes in perceptions of these four dimensions of school climate associated with changes in adolescents' problem behavior? Does gender moderate these associations? (3) Do adolescents' perceptions of school climate moderate the associations of deviant peer affiliations with problem behaviors?

Relevant to previous research, we hypothesized that adolescents' perceptions of academic support, school behavior management, teacher social support, and peer social support would decrease during the middle school years. We expected that girls would report more positive perceptions of the school environment and that these perceptions would decline less sharply over time than boys' perceptions. We also hypothesized that adolescents' perceptions of school climate and problem behaviors were negatively linked. That is, we expected to find that decreases in academic support, behavior management, teacher social support, and peer social support were associated with increases in problem behaviors. Finally, we hypothesized that the link between adolescent negative peer affiliation and problem behaviors was weaker for youth with more positive perceptions of school climate.

\section{METHOD}

\section{Sample}

Our data were collected as part of the Next Generation Project, a school-based program designed to increase understanding about how middle school parents and schools can work together to promote success, health, and well-being in the next generation of youth (Stormshak, Dishion, Light, \& Yasui, 2005). The project recruited adolescents from eight middle schools in a school district in the Pacific Northwest. Participating adolescents were followed from sixth through eighth grades. Schoolwide questionnaires were used to collect data from participating students and teachers in the spring of Year 1, winter of Year 2, and fall of Year 3. The initial sample of adolescents in the first year of data collection included 1,030 students from the 1,036 total consenting sixth graders (99\% completion rate). This sample at Year 1 comprised $69 \%$ of the total available sixth graders in the eight schools (consent rate). At Year 2 of collection, the sample comprised 1,069 adolescents of the 1,092 total consenting seventh graders (98\% completion rate). The sample at Year 2 represents $72 \%$ of the total available seventh graders (consent rate). At Year 3, the sample was 1,076 of the 1,106 total consenting eighth graders (97\% completion rate). The sample at Year 3 represented $72 \%$ of the total available eighth graders (consent rate). Of the adolescents surveyed in the first wave, 91\% completed all three waves.

Approximately $76 \%$ of participating adolescents were European American, 5\% Asian or Pacific Islander, 4\% Hispanic, 3\% American Indian, 1\% African American, and 11\% others. Approximately $54 \%$ of the adolescents were female. The percentage of adolescents participating in the free or reduced-price lunch program was $25 \%$. To ascertain whether the adolescents who dropped out of the study in any wave differed from the adolescents who participated in all three waves, a series of contingency table analyses and $t$-tests were conducted with all study variables at each wave. Statistically significant differences were not found between the two groups. It is noteworthy that this study's sample comprised primarily European American adolescents and thus is not representative of the general population. Therefore, generalizing from this sample must be done with caution.

\section{Procedure}

All students in the participating middle schools were sent a letter from the principal endorsing the Next Generation Project. Those students and their parents interested in participating in the study were asked to sign and return a youth and parental consent form. Phone calls, home visits, and classroom incentives (e.g., movie passes) were provided to maximize the return of consent forms. Participating adolescents who returned both youth and parental consent forms were assigned a school-based research number to ensure confidentiality. Schoolwide assessments were administered each year that included questionnaire data collection from participating adolescents, teachers, and peer reports regarding the participating students' behaviors. At each time of data collection, the Next Generation Project staff members visited each classroom and instructed the participating adolescents to complete the questionnaire during allotted class time. Incentives (e.g., movie passes) 
were given to adolescents during each session of data collection.

\section{Measures}

Adolescent and teacher self-report measures were administered to participants from sixth grade through eighth grade to measure students' perceptions of school climate and their problem behaviors, with a focus on externalizing behavior problems. All these measures have been validated in prior studies with this population (Stormshak et al., 2005).

Teacher reports of adolescent problem behavior. Teacher Perception of Risk (TRISK; Soberman, 1994) was used to assess the extent of adolescents' externalizing problem behaviors. The 16-item measure taps adolescents' classroom behavior, involvement in delinquency, and parents' contact with school. This scale began with the phrase "During the last three months, consider the extent to which each of the items below is true for this student." Example items were "argues a lot or uncooperative with the teacher," "misbehaves to get out of schoolwork," and "physically fights and/or bullies." All items were rated on a 6-point scale ranging from 1 (never true) to 6 (frequently recurring). The 16 items from the TRISK were averaged to measure adolescents' problem behavior on each occasion, with higher scores reflecting more problem behaviors. The measure has been used extensively with at-risk youth to assess problem behavior, and reliability and validity with populations in middle school and high school have been established (Biglan, Metzler, \& Ary, 1994). In the present study, the measure had good estimated internal consistency reliability $(\alpha=.87, .88, .85$, at Grades 6, 7, and 8, respectively).

Deviant peer affiliation. Four items from the student-report survey (Dishion \& Stormshak, 2002) were used to assess the extent of deviant peer affiliations. Example items included "In the last month, how often have you hung out with friends who get in trouble?", "How often have you hung out with friends who fight a lot?", "How often have you hung out with friends who take things that don't belong to them?", and "How often have you hung out with friends who smoke cigarettes or chew tobacco?" All items were rated on a 6-point scale ranging from 1 (never true) to 6 (frequently recurring). The four items were averaged on each occasion, with higher scores reflecting more deviant peer affiliations. The measure has good estimated internal consistency reliability and has been used in previous research to measure youth's affiliations with deviant peers (Dishion et al., 2004). In the present study, this measure demonstrated good internal consistency at each of the three time points $(\alpha=.86, .85, .83$, at Grades 6,7 , and 8, respectively).

School climate perceptions. Sixteen items were chosen from Dishion and Stormshak's (2002) School Climate Measure to assess adolescents' perceptions of school climate, including four subscales of the quality of school climate: academic support, school behavior management, teacher social support, and peer social support. The School Climate Measure scale is a widely used and well-validated measure (Dishion et al., 1991; Stormshak et al., 2005). Previous research has indicated that the measure has appropriate psychometric properties, including internal consistency and convergent and discriminant validity (Wang et al., 2010).

Academic support. The four items on this subscale assessed students' perceptions of academic support. Example items were "How many teachers in your school help students to organize their work?" and "How many teachers in your school help students to reach their goals for academic success?" Students responded using a 6-point scale ranging from 1 (none) to 6 (almost all). Student responses to the four items were averaged to create a subscale score for each grade. Higher scores indicated higher levels of academic support. This measure demonstrated good internal consistency at each of the three time points $(\alpha=.80, .81, .79$, at Grades 6, 7, and 8, respectively).

School behavior management. Four items were used to assess clarity and consistency in school rules and regulations. All items were rated on a six-point scale ranging from 1 (none) to 6 (almost all). Example items were "How many teachers give clear instructions about how to do their work in classes?" and "How many students understand what will happen to them if they break a rule in class?" The four items were averaged to create a subscale score of school behavior management on each occasion, with higher scores reflecting higher levels of behavior management. This measure demonstrated good internal consistency at each of the three time points $(\alpha=.81, .80, .82$, at Grades 6,7 , and 8 , respectively).

Teacher social support. Four items were used to assess teacher social support in the school. 
For each item, adolescents used a six-point scale ranging from 1 (none) to 6 (almost all). Example items were "How many teachers take a personal interest in students?" and "How many of the teachers in your school treat students with respect?" The four items were averaged to form a subscale score of teacher support on each occasion, with higher scores indicating higher levels of teacher social support. This scale yielded good internal consistency at each of the three time points $(\alpha=.83, .84$, .87 , at Grades 6, 7, and 8, respectively).

Peer social support. Four items were used to measure peer social support. Items involved the degree of peer positive interactions and affiliation with peers. The item response formats were sixpoint frequency scales ranging from 1 (none) to 6 (almost all). Example items were "How many of the students in your school are friendly to each other?" and "How many of the students in your school treat each other with respect?" Responses to these four items were averaged to create a subscale score of peer support, with higher scores reflecting more positive peer relationships. This scale yielded good internal consistency at each of the three time points ( $\alpha=.85, .88, .89$, at Grades 6,7 , and 8, respectively).

Covariates. As previous research has suggested that students' demographic characteristics can influence their subjective perceptions of the school climate, demographics were controlled in the statistical models as covariates. Demographic characteristics of the target sample included student ethnicity $(0=$ Non-White, $1=$ White $)$, socioeconomic status (SES), and gender $(0=$ Female, $1=$ Male). The school's categorization of student ethnicity was based on parents' reports when they enrolled their children in the school district. The SES indicator showed whether the student received free or reduced-cost lunch $(0=$ No, $1=$ Yes $)$.

Longitudinal confirmatory factor analysis (CFA) was conducted to examine the factorial invariance across time. We began with a minimally restricted CFA model in which the first item was used as a reference indicator at each time of measurement, and we added constraints to the model subsequently. The results indicated that both factor loadings and intercepts were invariant across time in the data.

\section{Analytic Strategy}

All models were estimated using a robust maximum likelihood estimation method in Mplus (Satorra \& Bentler, 1994), which is an appropriate way to estimate standard errors when normality assumptions are violated. We dealt with the missing data using full-information maximum likelihood estimation (FIML), which enabled us to include all available data. FIML assumes that the missing data are missing at random (MAR). For data MAR, missingness is a function of the observed variables in the model, and we addressed the assumptions of MAR through inclusion of covariates directly related to missingness (Widaman, 2006). The current data set includes students nested within eight public middle schools. We accounted for the nested nature of the data by fitting a multilevel model with random effects, and produced correctly adjusted standard errors in the model estimations. The following goodness-of-fit tests were used for both measurement and the structural models: the chi-square $\left(\chi^{2}\right)$ statistic to test the null-hypothesis of model fit, the comparative fit index (CFI), and the root meansquare error of approximation (RMSEA).

First, we ran a series of six latent growth models for each variable. Latent growth models specify intercept (initial status) and slope (rate of change) growth parameters and define within-person models. Covariance structure analyses enable the specification and test of relationships among different individual growth models and define the betweenperson models. A linear trajectory in growth was selected for the current model, because there were only three waves of data (Grades 6, 7 and 8). For the intercept to represent initial status in the sixth grade, we constrained the slope factor loadings at 0,1 , and 2. In addition, we tested adolescent gender differences on each of the six models using two-group analyses. Mean intercepts and slope factors were independently constrained to be equal for boys and for girls. A statistically significant chisquare between the constrained model and the unconstrained model indicated significant gender differences on the growth factor in this study.

Second, we used multivariate latent growth models to test associations between growth factors. We estimated all correlations between intercepts, correlations between intercept and slope factors, and correlations between slope factors simultaneously. Adolescent gender differences in associations between school climate perceptions and adolescent problem behaviors were examined. We used chi-square differences to compare the constrained model in which one association was constrained to be equal for boys and girls with an unconstrained model.

Finally, we examined the moderating effects of four dimensions of school climate on the association 
between deviant peer affiliation and problem behavior using multigroup analyses. Four dichotomous variables were created to capture adolescents' perceived academic support, school behavior management, teacher social support, and peer social support. We therefore differentiated latent classes of growth trajectories using median split at the baseline assessment. The first class, labeled high, had levels above the median in the four dimensions of school climate. Their median levels were 4.44 for academic support $(n=636), 4.68$ for behavior management $(n=606), 4.54$ for teacher social support $(n=628)$, and 4.58 for peer social support $(n=630)$. There were no significant changes over time for this group. The second class, labeled lower, had levels below the median in the four dimensions of school climate. Their median levels were 3.01 for academic support $(n=592)$, 3.36 for behavior management $(n=632), 2.96$ for teacher social support $(n=600)$, and 3.02 for peer social support $(n=608)$. The four dichotomous variables of school climate were used as grouping variables in the growth models. For each occasion, we tested moderating effects by constraining the association to be equal for the high and lower school climate group and subsequently testing whether such constraint would increase the chisquare value of the model. The significant gender differences were still allowed to be free in the moderation models.

\section{RESULTS}

Table 1 provides the means, standard deviations, skewness, and correlations among the perceptions of school climate and the outcome variables. The analyses of means show declines in the students' perceptions of middle school climate, whereas adolescents' affiliation with deviant peers and problem behaviors increased. The skewness coefficients ranged from -0.22 to 2.02 , thereby providing little evidence of significant deviations from symmetry. The four dimensions of school climate perceptions were moderately and positively related to each other. The four dimensions of school climate perceptions were negatively related to adolescents' problem behaviors.

\section{Trajectories of Perceived School Climate and Adolescent Problem Behaviors}

Table 2 shows the estimated developmental changes during middle school. For the four dimensions of school climate, there were significant individual differences in the average level of perceived academic support, school behavior management, teacher social support, and peer social support in the sixth grade (i.e., different from zero). In addition, individual differences were found in the slope for perceived academic support and school behavior management, both showing significant decline over the course of middle school. Similarly, students' perceptions of teacher support and peer support decreased as they progressed through middle school. Finally, there were significant increases in adolescents' problem behavior and delinquent peer affiliations over time.

Significant gender differences were found, with girls reporting more academic support, $\Delta \chi^{2}(1, N=$ $1,030)=7.95, p<.01$; school behavior management, $\Delta \chi^{2}(1, N=1,030)=10.57, p<.01$; teacher social support, $\Delta \chi^{2}(1, N=1,030)=13.84, p<.01$; and peer social support, $\Delta \chi^{2}(1, N=1,030)=9.47, p<.01$ than boys did, but less problem behaviors than boys did at the sixth grade, $\Delta \chi^{2}(1, N=1,030)$ $=11.14, p<.001$. Moreover, boys engaged in more problem behaviors than did girls over time, $\Delta \chi^{2}$ $(1, N=1,030)=12.32, p<.001$. There were no gender differences in the rates of change in the four dimensions of school climate perceptions and deviant peer affiliations.

\section{Associations Between Perceived School Climate and Problem Behaviors}

The second question of this study had to do with examining the covariation between perceived school climate and the development of problem behavior from sixth through eighth grades. Results of the multivariate models are shown in Table 3. Consistent with our hypothesis, correlations were found between mean levels of each of the four school climate variables and mean levels in teacherreported problem behavior over time. Similarly, changes (i.e., the slope) of each of the school climate variables were associated with changes in teacherreported problem behavior. In all cases, declines in adolescents' perceptions of the school climate were correlated with increases in teacher report of adolescent problem behavior from sixth to eighth grades. Furthermore, the rate of change in delinquent peer affiliations was associated with the rate of change in adolescents' problem behavior. As adolescents reported increases in negative peer affiliations, there were corresponding increases in their problem behaviors.

In summary, adolescents' perceptions of academic support, school behavior management, teacher social 


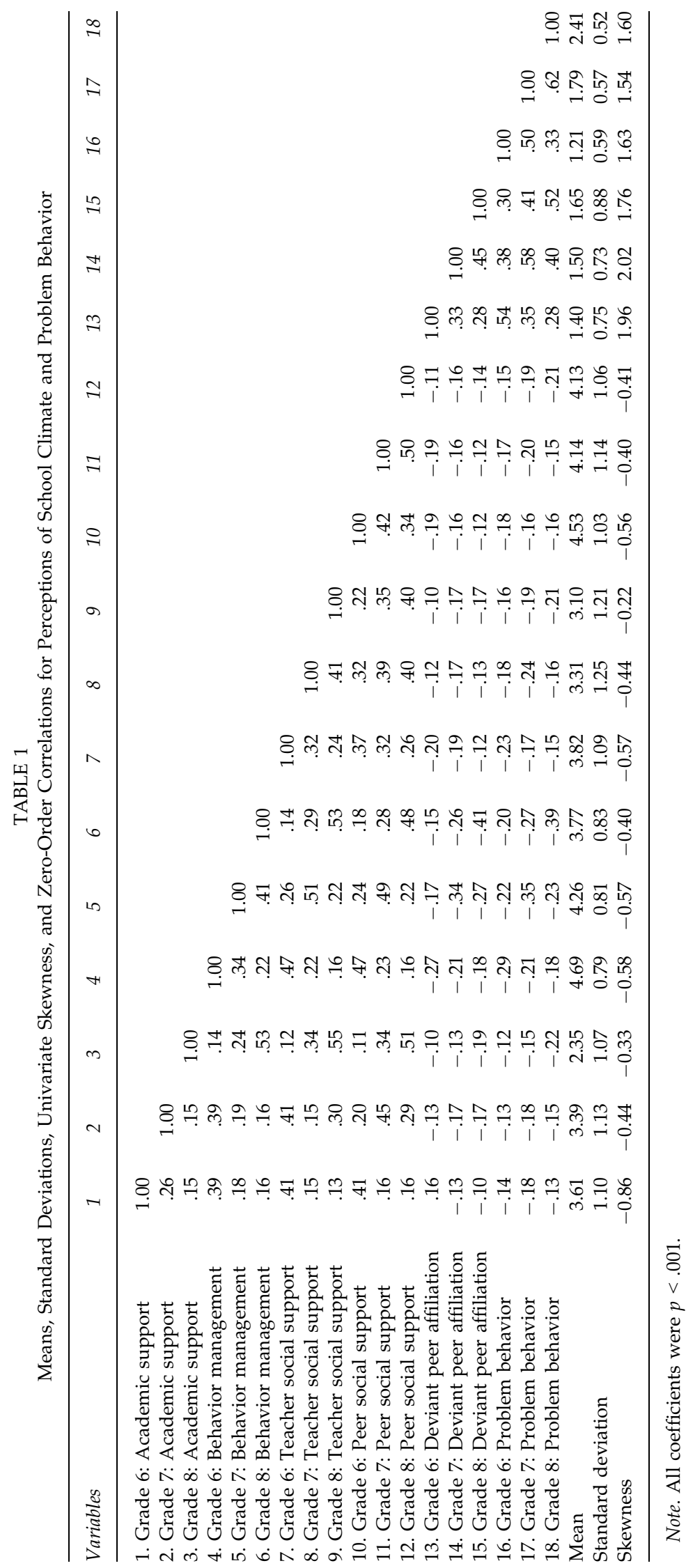


TABLE 2

Estimated Levels and Rates of Change for Five Univariate Latent Growth Models

\begin{tabular}{|c|c|c|c|c|c|c|c|c|c|c|c|c|}
\hline \multirow{3}{*}{$\frac{\text { Model }}{\text { Academic support }}$} & \multicolumn{4}{|c|}{ Intercept (mean level) } & \multicolumn{4}{|c|}{ Slope (rates of change) } & \multirow{2}{*}{$\begin{array}{c}\text { Association Between } \\
\text { Intercept and Slope }\end{array}$} & \multicolumn{3}{|c|}{ Model Fit } \\
\hline & \multicolumn{2}{|c|}{$M(S E)$} & \multicolumn{2}{|c|}{ Variance (SE) } & \multicolumn{2}{|c|}{$M(S E)$} & \multicolumn{2}{|c|}{ Variance (SE) } & & $X^{2}(d f)$ & RMSEA & CFI \\
\hline & $3.65^{* * *}$ & $(0.03)$ & $0.47^{* * *}$ & $(0.07)$ & $-0.58^{* * *}$ & $(0.04)$ & $0.07^{* * *}$ & $(0.02)$ & $-0.44^{* * *} \quad(0.09)$ & $53.91(3)$ & .05 & .97 \\
\hline $\begin{array}{l}\text { Behavior } \\
\text { management }\end{array}$ & $4.70^{* * *}$ & $(0.03)$ & $0.29^{* * *}$ & $(0.06)$ & $-0.46^{* * *}$ & $(0.02)$ & $0.09^{* *}$ & $(0.03)$ & $-0.05 \quad(0.04)$ & $17.36(3)$ & .05 & .96 \\
\hline $\begin{array}{l}\text { Teacher social } \\
\text { support }\end{array}$ & $3.64^{* * *}$ & $(0.04)$ & $0.38^{* * *}$ & $(0.06)$ & $-0.22^{* * *}$ & $(0.02)$ & $0.08^{* *}$ & $(0.03)$ & $-0.24^{* * *} \quad(0.04)$ & 24.07 (3) & .04 & .97 \\
\hline $\begin{array}{l}\text { Peer social } \\
\text { support }\end{array}$ & $4.02^{* * *}$ & $(0.03)$ & $0.53^{* * *}$ & $(0.07)$ & $-0.20^{* * *}$ & $(0.02)$ & $0.06^{* *}$ & $(0.02)$ & $-0.28^{* * *} \quad(0.05)$ & $44.24(3)$ & .05 & .95 \\
\hline Problem behavior & $1.21^{* * *}$ & $(0.02)$ & $0.08^{* * *}$ & $(0.01)$ & $0.61^{* * *}$ & $(0.08)$ & $0.04^{* * *}$ & $(0.01)$ & $0.26^{* *} \quad(0.08)$ & $10.07(3)$ & .04 & .98 \\
\hline $\begin{array}{l}\text { Deviant peer } \\
\text { affiliation }\end{array}$ & $1.45^{* * *}$ & $(0.03)$ & $0.16^{* * *}$ & $(0.04)$ & $0.12^{* *}$ & $(0.04)$ & $0.09^{* * *}$ & $(0.02)$ & $-0.05^{*} \quad(0.02)$ & $9.71(3)$ & .03 & .99 \\
\hline
\end{tabular}

Note. CFI, comparative fit index; RMSEA, root mean-square error of approximation.

${ }^{*} p<.05 ;{ }^{* *} p<.01 ;{ }^{* * *} p<.001$.

TABLE 3

Associations Between Growth Factors From Multivariate Models

\begin{tabular}{|c|c|c|c|c|}
\hline \multirow{3}{*}{$\frac{\text { Estimated Path }}{\text { Level of academic support }}$} & \multicolumn{2}{|c|}{$\begin{array}{c}\text { Associations With Level of Problem } \\
\text { Behaviors }\end{array}$} & \multicolumn{2}{|c|}{$\begin{array}{c}\text { Associations With Change in Problem } \\
\text { Behaviors }\end{array}$} \\
\hline & $B(S E)$ & $\beta(S E)$ & $B(S E)$ & $\beta(S E)$ \\
\hline & $-.07^{* * *} \quad(.01)$ & $-.34^{* * *}(.05)$ & $-.37^{*}(.18)$ & $-.11^{*}(.05)$ \\
\hline Level of behavior management & $-.14^{* * *} \quad(.01)$ & $-.65^{* * *} \quad(.06)$ & $-.64^{* * *}(.13)$ & $-.25^{* * *}(.07)$ \\
\hline Level of teacher social support & $-.13^{* * * *} \quad(.02)$ & $-.39^{* * *} \quad(.06)$ & $-.26 \quad(.18)$ & $-.07 \quad(.04)$ \\
\hline Level of peer social support & $-.10^{* * *} \quad(.02)$ & $-.34^{* * *} \quad(.07)$ & $-.26 \quad(.17)$ & $-.06 \quad(.04)$ \\
\hline Level of deviant peer affiliation & $.05^{*} \quad(.02)$ & $.19^{*} \quad(.08)$ & $.13 \quad(.11)$ & $.06 \quad(.05)$ \\
\hline Change in academic support & $-.01 \quad(.02)$ & $-.14 \quad(.10)$ & $-.25^{*}(.12)$ & $-.10^{*} \quad(.04)$ \\
\hline Change in behavior management & $-.01 \quad(.01)$ & $-.12 \quad(.09)$ & $-.31^{* *}(.10)$ & $-.10^{* *} \quad(.03)$ \\
\hline Change in teacher social support & $-.02 \quad(.01)$ & $-.15 \quad(.10)$ & $-.44^{* * *} \quad(.12)$ & $-.19^{* * *} \quad(.05)$ \\
\hline Change in peer social support & $-.01 \quad(.01)$ & $-.14 \quad(.10)$ & $-.48^{* * * *} \quad(.11)$ & $-.20^{* * *} \quad(.05)$ \\
\hline Change in deviant peer affiliation & $.03^{* *} \quad(.01)$ & $.26^{* *} \quad(.09)$ & $.67^{* * *} \quad(.09)$ & $.40^{* * *} \quad(.05)$ \\
\hline
\end{tabular}

Note. Fit statistics indicated adequate model fit for the final model, $\chi^{2}(81)=936.34, p<.001, \mathrm{CFI}=.94, \mathrm{RMSEA}=.04$.

CFI, comparative fit index; RMSEA, root mean-square error of approximation.

${ }^{*} p<.05 ;{ }^{* *} p<.01 ;{ }^{* * * *} p<.001$.

support, and peer social support in sixth grade were significantly associated with teachers' reported levels of problem behaviors in sixth grade. In addition, adolescents who reported a decline in academic support and in school behavior management, in conjunction with a perceived reduction in social support from teachers and peers, experienced increases in problem behaviors over time. Finally, adolescents who had increased affiliations with deviant peers had increased problem behaviors.

We subsequently tested for gender differences in associations between intercepts and slopes of school climate perceptions and the intercepts and slopes of problem behaviors. Overall, the strength of associa- tions between perceived school climate and problem behaviors was equivalent across gender, with the exception that reductions in perceived peer support and increases in problem behavior were slightly stronger for girls than for boys, $\Delta \chi^{2}(1, N=$ $1,030)=5.62, p=.02$. There were no gender differences in the association between changes in delinquent peer affiliations and changes in adolescents' problem behaviors.

\section{School Climate as a Moderator Between Deviant Peer Affiliations and Problem Behavior}

To examine the moderation effect of school climate, we tested whether associations between deviant 
peer affiliation on the one hand and adolescents' problem behavior on the other hand differed for youths with high and lower academic support, behavior management, teacher social support, and peer social support, respectively. We found that the positive association between levels of deviant peer affiliation and levels of problem behaviors was significantly weaker for youths with high perceived school behavior management than for youths with lower perceived school behavior management, $\Delta \chi^{2}(1, \quad N=1,030)=8.79, p<.01$. The positive association between the rate of change in deviant peer affiliation and the rate of change in problem behavior was significantly moderated by perceived behavior management, with nonsignificant effect in the high perceived behavior management group, $\Delta \chi^{2}(1, N=1,030)=12.45, p<.001$. In addition, we found that the positive association between the rate of change in deviant peer affiliation and the rate of change in problem behaviors was significantly weaker for adolescents with high perceived teacher social support than those with lower perceived teacher social support, $\Delta \chi^{2}(1, N=$ $1,030)=10.04, p<.01$. No moderation effect was found on intercept-intercept or intercept-slope associations.

\section{DISCUSSION}

\section{Trajectories of Perceived School Climate and Problem Behavior}

This longitudinal study aimed to examine changes in adolescents' perceptions of academic support, school behavior management, teacher and peer social support, the effects of these changes on adolescents' externalizing problem behaviors, and the moderating role of school climate perceptions between peer affiliation and adolescent problem behavior from sixth through eighth grades. Our findings revealed that adolescents' perceptions of all four dimensions of school climate decreased throughout the middle school years for both genders, and adolescents' problem behaviors increased. The decline in perceptions of school climate may reflect an interactive process of decreasing school engagement and increased involvement with deviant peer groups and problem behavior. This developmental trend that applies, in general, to all young adolescents may well result from a mismatch between adolescents' psychological needs (e.g., relatedness and autonomy) and school environment (Eccles et al., 1991; Wang, 2009). For instance, having many teachers and fewer interactions with each teacher is inconsistent with the student's need for deep relationships with adults outside their family. Similarly, at a time when adolescents are developing their sense of independence and autonomy, middle schools have greater structure and fewer choices (Eccles et al., 1995). Adolescents who cannot adjust to changes in school or meet new expectations might report a decrease in school satisfaction, bonding to school, and performance during the middle school years.

In terms of gender difference in the perceived school climate, we found that girls reported better academic support, school behavior management, teacher social support, and peer social support than did boys in the sixth grade. It is plausible that social expectations placed upon girls are more similar to those placed upon "good" students than are the expectations placed on boys (Samdal, Nutbeam, Wold, \& Kannas, 1998). For example, good students are expected to be cooperative with teachers' directions, attentive and adult-oriented, and confident about using verbal and reading skills. These attributes coincide more strongly with traditional female gender roles and differ from traditional male gender roles. As such, boys may have more difficulty meeting the expectations of teachers; in turn, their difficulties in school may result in further negative perceptions about school. However, our findings did not indicate that boys experienced sharper declines in the four dimensions of school climate than did girls from sixth through eighth grades. It seems that compared with girls, boys are not prevented by these gender biases and beliefs from perceiving their school environment as decreasingly supportive and positive over time.

\section{The Association Between School Climate and Problem Behavior}

In line with our hypotheses, the study findings demonstrate the negative associations between the rates of change in the four dimensions of perceived school climate and the rate of change in problem behaviors. Adolescents who perceived declines in academic support, school behavior management, teacher social support, and peer social support in school engaged in increased externalizing problem behaviors over time. The findings suggest that perceived school climate is not static, but continues to change over time. Therefore, it is necessary to take into account the dynamic nature of these associations when examining the mutual influence between school climate perceptions and behavioral adjustment. 
Analyses examining gender differences suggested that most of the associations between school climate perceptions and problem behaviors were consistent across gender. Only one gender difference emerged. Although many adolescents who experienced decreased prosocial peer social support had increased problem behaviors, this effect was stronger for girls. In other words, changes in peer social support are a more powerful risk factor for girls than for boys. It is plausible that peer social support is particularly salient for girls, because for them socialization emphasizes the importance of interpersonal relationships (Rueger, Malecki, \& Demaray, 2008). Feeling support from peers in school decreases the possibility that girls will experience peer conflict and consequently engage in delinquency. Girls are also more sensitive to the social pressures in the school environment than are boys, both in terms of appeasing school personnel and conforming to peer pressure (Kerr, Preuss, \& Ling, 2006). We might therefore conclude that girls are more likely to be susceptible to the risk factor of less positive peer social support.

\section{School Climate as a Moderator Between Deviant Peer Affiliations and Problem Behavior}

This study provides evidence of moderating effects of certain dimensions of school climate on the association between deviant peer affiliations and problem behaviors. As expected, increases in deviant peer affiliations were associated with more problem behavior for both male and female students. High-risk peer groups provide more opportunities for modeling and supporting deviant behavior, and they organize their relationships around the promotion of deviance (Dishion et al., 2004; Patterson, Dishion, \& Yoerger, 2000). However, the positive association between adolescents' deviant peer affiliations and their problem behaviors was weaker for youths experiencing high levels of school behavior management compared with those with low school behavior management. Adolescents' experiences of better school behavior management appeared to counteract the negative effect of deviant peer affiliations on problem behaviors. Adolescents who recognize the validity of school rules for maintaining a safe school environment and who follow those rules will be less likely to spend time with deviant peers and engage in delinquent behaviors subsequently (Welsh, Stokes, \& Greene, 2001).

In addition, high levels of teachers' care, support, and respect for individual students appear to deter the influence of deviant peer groups on adolescents' problem behaviors, as this study indicates. Research has suggested that adolescents characterized by externalizing and comorbid difficulties were more likely to engage with deviant peer groups (Dishion, 2000). Students' perceptions of supportive student-teacher relationships may help establish a sense of community or connection to the school and in turn reduce the risk of emotional distress and increase support of socially acceptable behavior (Loukas, Roalson, \& Herrera, 2010).

Given that the transition to middle school might be a stressful factor for early adolescents, the results regarding a positive student-teacher relationship support targeting the emotional and psychological elements of school climate when designing school prevention programs. In addition to maintaining a well-disciplined, organized school structure and consistent rule enforcement, schools would do well to nurture a high-quality relational environment, instruct teachers to provide students with encouragement and praise for on-task behaviors, and help teachers deliver group contingencies through practical classroom management strategies.

\section{Limitations}

This study has some limitations that merit consideration. First, the study's data rely upon self-report information from students to assess perceptions of school climate, and this strategy raises an important validity concern. Social desirability problems may be operating in that the preferred behavior may influence the students' perceptions of school climate. Future research should examine both the subjective and objective aspects of school climate and compare their influences on adolescents' behavioral adjustment. The use of multiple sources of information about the school environment (informants, teachers, principals, parents) and multiple methodologies (interviews, observations, surveys) can also provide a more robust, valid method for identifying school effects (Kasen, Johnson, \& Cohen, 1990).

Second, this study's sample comprises primarily European American middle school students and indicates very little ethnic diversity. Therefore, these findings may be limited in their generalizability to more diverse populations. Third, the results indicated that most of the variation in school climate perceptions exists at the individual level, possibly because of the limited number of schools (eight schools) in the study. Thus, future studies 
should examine the impact of school-level climate in addition to individual-level climate perceptions on student behavior problems. Finally, the study identified the protective roles of specific aspects of students' perceptions of school climate on their problem behaviors. However, little is known about processes relevant to how students' perceptions of school climate mediate their subsequent problem behaviors. Future research examining the mediators would extend our understanding of the processes underlying school climate effects (Loukas \& Murphy, 2007).

\section{Conclusion}

Educators face a series of challenges as they address adolescent problem behaviors. This research lends support to existing studies and demonstrates that the interactions and experiences that adolescents have in school have an enduring effect on their behavioral development. Our study has further indicated the importance of creating a school setting that adolescents perceive to be orderly and structured, a place where all students interact appropriately and where student-teacher relationships are positive. Creating such an environment might improve the quality of educational experience of the students, and reduce the development of problem behaviors. With a thorough understanding of how school climate can be a protective factor against deviant peer affiliation and further problem behaviors, schools can establish effective prevention and environments to support adolescents' social and behavioral development.

\section{REFERENCES}

Biglan, A., Metzler, C. W., \& Ary, D. V. (1994). Increasing the prevalence of successful children: The case for community intervention research. The Behavior Analyst, 17, 335-351.

Bronfenbrenner, U. (1986). Ecology of the family as a context for human development. Developmental Psychology, 22, 723-742.

Bullock, B. M., Deater-Deckard, K., \& Leve, L. (2006). Deviant peer affiliation and problem behavior: A test of genetic and environmental influences. Journal of Abnormal Psychology, 34, 29-41.

Cleveland, H. H., \& Wiebe, R. P. (2003). The moderation of adolescent-to-peer similarity in tobacco and alcohol use by school levels of substance use. Child Development, 74, 279-291.

Coie, J. D., \& Kupersmidt, J. B. (1983). A behavioral analysis of emerging social status in boys' groups. Child Development, 54, 1400-1416.
Colarossi, L. G., \& Eccles, J. S. (2003). Differential effects of support providers on adolescents' mental health. Social Work Research, 27, 19-30.

Connell, J. P., \& Wellborn, J. G. (1991). Competence, autonomy, and relatedness: A motivational analysis of self-system processes. In M. R. Gunnar \& L. A. Sroufe (Eds.), Self-processes in development: Minnesota Symposium on Child Psychology (Vol. 23, pp. 43-77). Chicago, IL: University of Chicago Press.

Crone, D. A., \& Horner, R. H. (2003). Building positive behavior support systems in schools: Functional behavioral assessment. New York, NY: Guilford.

Crosnoe, R., Erickson, K. G., \& Dornbusch, S. M. (2002). Protective functions of family relationships and school factors on the deviant behavior of adolescent boys and girls: Reducing the impact of risky friendships. Youth and Society, 33, 515-544.

Dishion, T. J. (2000). Cross-setting consistency in early adolescent psychopathology: Deviant friendships and problem behavior sequelae. Journal of Personality, 68, 1109-1126.

Dishion, T. J., Bullock, B. M., \& Granic, I. (2002). Pragmatism in modeling peer influence: Dynamic, outcomes, and change processes. Development and Psychopathology, 14, 969-981.

Dishion, T. J., Nelson, S. E., Winter, C. E., \& Bullock, B. M. (2004). Adolescent friendship as a dynamic system: Entropy and deviance in the etiology and course of male antisocial behavior. Journal of Abnormal Child Psychology, 32, 651-663.

Dishion, T. J., \& Patterson, G. R. (2006). The development and ecology of antisocial behavior. In D. Cicchetti \& D. J. Cohen (Eds.), Developmental psychopathology: Vol. 3. Risk, disorder, and adaptation (2nd ed., pp. 503-541). Hoboken, NJ: Wiley.

Dishion, T. J., Patterson, G. R., Stoolmiller, M., \& Skinner, M. (1991). Family, school, and behavioral antecedents to early adolescent involvement with antisocial peers. Developmental Psychology, 27, 172-180.

Dishion, T. J., \& Stormshak, E. A. (2002). Social nominations. Unpublished measure. Child and Family Center, Eugene, OR 97401.

Dodge, K. A. (1983). Behavioral antecedents: A peer social status. Child Development, 54, 1386-1399.

Eccles, J. S., Lord, S., \& Midgley, C. (1991). What are we doing to early adolescents? The impact of educational contexts on early adolescents. American Journal of Education, 99, 521-542.

Eccles, J. S., Lord, S. E., \& Roeser, R. W. (1995). Round holes, square pegs, rocky roads, and sore feet: The impact of stage-environment fit on young adolescents' experiences in schools and families. In D. Cicchetti \& S. Toth (Eds.), Rochester Symposium on Developmental Psychopathology: Adolescence: Opportunities and challenges (Vol. 7, pp. 47-92). Rochester, NY: University of Rochester Press.

Eccles, J. S., Midgley, C., Buchanan, C. M., Flanagan, C., MacIver, D., \& Reuman, D. et al. (1993). Development 
during adolescence: The impact of stage/environment fit. American Psychologist, 48, 90-101.

Ensminger, M. E., Kellam, S. G., \& Rubin, B. R. (1981). School and family origins of delinquency: Comparisons by sex. In K. T. V. Dusen \& S. A. Mednick (Eds.), Prospective studies of crime and delinquency (pp. 234-258). Boston, MA: Kluwer-Nijhoff.

Gottfredson, D. (1990). Changing school structures to benefit high-risk youth. In P. Leone (Ed.), Understanding troubled and troubling youth: Multidisciplinary perspectives (pp. 123-135). Newbury Park: Sage.

Gottfredson, D. C., Gottfredson, G. D., \& Hybl, L. G. (1993). Managing adolescent behavior: A multiyear, multischool study. American Educational Research Journal, 30, 179-215.

Gottfredson, G. D., \& Gottfredson, D. C. (2001). What schools do to prevent problem behavior and promote safe environments. Journal of Educational and Psychological Consultation, 12, 313-344.

Griffith, J. (1999). School climate as "social order" and "social action": A multi-level analysis of public elementary school student perceptions. School Psychology of Education, 2, 339-369.

Kasen, S., Johnson, J., \& Cohen, P. (1990). The impact of school emotional climate on student psychopathology. Journal of Abnormal Psychology, 18, 165-177.

Kerr, D. C., Preuss, L. J., \& Ling, C. A. (2006). Suicidal adolescents' social support from family and peers: Gender-specific associations with psychopathology. Journal of Abnormal Child Psychology, 34, 103-113.

Kuperminc, G. P., Leadbeater, B. J., \& Blatt, S. J. (2001). School social climate and individual differences in vulnerability to psychopathology among middle school students. Journal of School Psychology, 39, 141-159.

Kuperminc, G. P., Leadbeater, B. J., Emmons, C., \& Blatt, S. J. (1997). Perceived school climate and difficulties in the social adjustment of middle school students. Applied Developmental Science, 1, 76-88.

Loukas, A., \& Murphy, J. L. (2007). Middle school student perceptions of school climate: Examining protective functions on subsequent adjustment problems. Journal of School Psychology, 45, 293-309.

Loukas, A., Roalson, L. A., \& Herrera, D. E.. (2010). School connectedness buffers the effects of negative family relations and poor effortful control on early adolescent conduct problems. Journal of Research on Adolescence, 20, 13-22.

Loukas, A., \& Robinson, S. (2004). Examining the moderating role of perceived school climate in early adolescent adjustment. Journal of Research on Adolescence, 14, 209-233.

McEvoy, A., \& Welker, R. (2000). Problem behavior, academic failure, and school climate: A critical review. Journal of Emotional and Behavioral Disorders, 8, 130-141.

Nelson, S. E., \& Dishion, T. J. (2004). From boys to men: Predicting adult adaptation from middle childhood sociometric status. Development and Psychopathology, 16, 441-459.
Patterson, G. R., Dishion, T. J., \& Yoerger, K. (2000). Adolescent growth in new forms of problem behavior: Macro- and micro-peer dynamics. Prevention Science, 1, 3-13.

Reinke, W. M., \& Herman, K. C. (2002). Creating school environments that deter problem behaviors in youth. Psychology in the Schools, 39, 549-559.

Roeser, R. W., \& Eccles, J. S. (1998). Adolescents' perceptions of middle school: Relation to longitudinal changes in academic and psychological adjustment. Journal of Research on Adolescence, 8, 123-158.

Roeser, R. W., Eccles, J. S., \& Sameroff, A. J. (2000). School as a context of early adolescents' academic and social-emotional development: A summary of research findings. Elementary School Journal, 100, 443-471.

Rueger, S. Y., Malecki, C. K., \& Demaray, M. K. (2008). Gender differences in the relationship between perceived social support and student adjustment during early adolescence. School Psychology Quarterly, 23, 496514.

Samdal, O., Nutbeam, D., Wold, B., \& Kannas, L. (1998). Achieving health and educational goals through schools-A study of the importance of the school climate and the students' satisfaction with school. Health Education Research, 13, 383-397.

Satorra, A., \& Bentler, P. M. (1994). Corrections to test statistics and standard errors in covariance structure analysis. In A. von Eye \& C. C. Clogg (Eds.), Latent variables analysis: Applications for developmental research (pp. 399-419). Thousand Oaks, CA: Sage.

Seidman, E., Allen, L., Aber, J. L., Mitchell, C., \& Feinman, J. (1994). The impact of school transitions in early adolescence on the self-system and perceived social context of poor urban youth. Child Development, 65, 507-522.

Simons-Morton, B. G., Crump, A. D., Haynie, D. L., \& Saylor, K. E. (1999). Student-school bonding and adolescent problem behavior. Health Education Research, 14, 99-107.

Soberman, L. (1994). Psychometric validation of a brief teacher screening instrument (TRISK). Unpublished doctoral dissertation, University of Oregon, Eugene, OR.

Stewart, E. A.. (2003). School social bonds, school climate, and school misbehavior: A multilevel analysis. Justice Quarterly, 20, 575-604.

Stormshak, E. A., Dishion, T. J., Light, J., \& Yasui, M. (2005). Implementing family-centered interventions within the public middle school: Linking service delivery change to change in problem behavior. Journal of Abnormal Child Psychology, 33, 723-733.

Wang, M. T. (2009). School climate support for behavioral and psychological adjustment: Testing the mediating effect of social competence. School Psychology Quarterly, 24, 240-251.

Wang, M. T., Dishion, T. J., Stormshak, E. A., \& Willett, J. B. (2011, June 20). Trajectories of family management practices and early adolescence behavioral outcomes in middle school. Developmental Psychology. Advance online publication. doi:10.1037/a0024026. 
Wang, M. T., \& Eccles, J. S. (in press-a). Social support matters: Longitudinal effects of social support on three dimensions of school engagement from middle to high school. Child Development.

Wang, M. T., \& Eccles, J. S. (in press-b). Adolescent behavioral, emotional, and cognitive engagement trajectories in school and their differential relations to educational success. Journal of Research on Adolescence.

Wang, M. T., \& Holcombe, R. (2010). Adolescents' perceptions of school environment, engagement, and academic achievement in middle school. American Educational Research Journal, 47, 663-662.

Wang, M. T., Selman, R. L., Dishion, T. J., \& Stormshak, E. A. (2010). A tobit regression analysis of the covariation between middle school students' perceived school climate and problem behavior. Journal of Research on Adolescence, 20, 274-286.

Way, N., \& Greene, M. L. (2006). Trajectories of perceived friendship quality during adolescence: The patterns and contextual predictors. Journal of Research on Adolescence, 16, 293-320.

Way, N., Reddy, R., \& Rhodes, J. (2007). Students' perceptions of school climate during the middle school years: Associations with trajectories of psychological and behavioral adjustment. American Journal of Community Psychology, 40, 194-213.

Weishew, N. L., \& Peng, S. (1993). Variables predicting students' problem behaviors. Journal of Educational Research, 87, 5-17.

Welsh, W. N., Stokes, R., \& Greene, J. R. (2001). A macro-level model of school disorder. Journal of Quantitative Criminology, 3, 65-81.

Wentzel, K. R. (1998). Social relationships and motivation in middle school: The role of parents, teachers, and peers. Journal of Educational Psychology, 90, 202-209.

Widaman, K. (2006). Missing data: What to do with or without them. Monographs of the Society for Research in Child Development, 71, 42-64. 